\title{
Finding the Expected Probability of Maximum Temperature and Forecast of the City Baghdad in the Winter using Generalized Weibull Distribution
}

\author{
Saleemah H. Jasaim Al Saady ${ }^{1}$, Iftikhar Ali Hussein Khamies ${ }^{2}$ \\ ${ }^{1}$ Department of Astronomy and Space, College of Science, Baghdad University, Baghdad, Iraq \\ ${ }^{2}$ Department of Computer Systems Technologies, Institute of Technical Management, Baghdad, Iraq
}

\begin{abstract}
The study was an application on Weibull distribution Probability of maximum temperature degrees and rains data for city of Baghdad during (2000-2010) for ten years taken from Meteorological Network of Iraqi Ministry of Agriculture. The results indicated to the possibility of using the generalized Weibull distribution in finding the expected Probability of the maximum temperature degrees and forecast possibility.
\end{abstract}

Keywords: generalized Weibull distribution, Exponential distribution, Taylor serial, Linear Regression, Wight method-least squares method (OLS).

\section{Introduction}

The estimated Probability Weibull distribution can be used in forecasting the expected Probability of Meteorology and its future directions for Baghdad city with comparing between. The actual and estimated data especially Weibull distribution (with negative torsion), in $1990 \mathrm{Al}$. Baidhen F. A has find an alternative form to distribute Weibull, called it generalized Weibull distribution to exceed its indicator value and suggest a new form least squares method (OLS) which its parameter value was (3.6). Since Probability generalized Weibull distribution insure its effectiveness in estimating, therefore, our research focused on theoretical and applied knowledge for estimating methods of parameters distribution and its affectedness and the possibility of expected Probability for Meteorology and the future directions of Baghdad city with the possibility of comparing between its actual and estimated data.

\section{The Research Hypothesis will be}

1) The convenient of maximum temperature degrees data and estimated rains amounts to distribute generalized Weibull with two parameter.

2) Identification of the real and estimated values through ProbabilityWeibull distribution.

\subsection{Weibull distribution:}

The random variable $(\mathrm{X})$ which subject to Weibull distribution in three indicators $(\mathrm{k}, \lambda, \theta)$. $\mathrm{k}$ (Shape Parameter, $\lambda$ represents Scale Parameter indicator and $\theta$ represents Location Parameter, provided that $(\mathrm{k}<0),(\lambda>0), \theta$ (is a real number), therefore the density follower will be as following:

$$
\begin{aligned}
& \mathrm{f}(\mathrm{x})=\left\{\begin{array}{ll}
0 & \text { if } \quad x \leq 0 \\
\frac{k}{\gamma}\left(\frac{x-\theta}{\gamma}\right)^{k-1} & e^{-}\left(\frac{x-\theta}{\gamma}\right)^{k} x>0
\end{array}\right\} \\
& \text { We put }\left(\beta=k,\left(\frac{k}{\gamma}=\alpha\right) \text { and }\left(x=\frac{x-\theta}{\gamma}\right)\right)
\end{aligned}
$$

We can write the relation as:

$$
f(x)=\left\{\begin{array}{lll}
0 & \text { if } & x \leq 0 \\
& \alpha(X)^{\beta-1} e^{-(x) \beta} & x>0
\end{array}\right\}
$$

give continued density:

$$
F(x)=\left\{\begin{array}{lr}
0 & \text { if } \quad x \leq 0 \\
1-e^{-(x)^{\beta}} & X>0
\end{array}\right\}
$$

Explain Figure (1) shows the graph width of densities

Placing in relation 1 graphic of density symmetrical and frequent of Weibull distribution to be $(\theta=0)(\lambda=1)$ for different values of $(\mathrm{k})$ between $(3,0.5)$ as follows The shape is density function of Weibull distribution (shape 1)

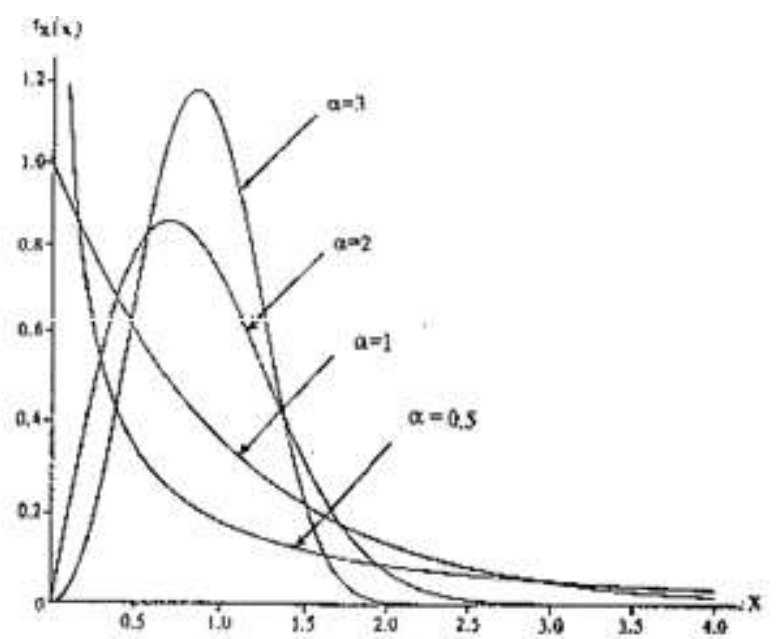

Figure 1: Continued (function) density distribution Weibull

Depending on Weibull distribution follower the intensity as in shape (1), we will have generalized Weibull distribution and schedule of its distribution followers, where these schedules with the same indicators that previously mentioned, because according to the following theory the random variable $(\mathrm{x})$ subjects to Weibull distribution with the parameters $(\mathrm{k}, \lambda, \theta)$ as it subject to the random variable $(\mathrm{x})$ for Weibull distribution $\mathrm{y}=-(\mathrm{X} /(\lambda)) \mathrm{kfor}$ generalized Weibull distribution so the expected value and variance for this distribution.[8] 


\section{International Journal of Science and Research (IJSR)}

ISSN (Online): 2319-7064

Index Copernicus Value (2016): 79.57 | Impact Factor (2015): 6.391

$$
\begin{array}{r}
\mu=E(X)=\gamma \Gamma\left(\frac{1}{k}+1\right) \ldots \ldots \ldots \ldots . . \\
\sigma^{2}=\beta^{2}(x)=\gamma^{2}\left(\Gamma\left(\frac{2}{k}+1\right)-\Gamma^{2}\left(\frac{1}{k}+1\right) \ldots\right.
\end{array}
$$

$\Gamma$ Continued distribution of the Gama

$\Gamma(1)=1$

$\Gamma(1 / 2)=\sqrt{ } \pi$

$\Gamma(\mathrm{x})=(\mathrm{x}-1) \cdot \Gamma(\mathrm{x}-1)$

When $(\theta=1)$ Weibull distribution with two parameter Density function as

$$
f(x)=\left\{\begin{array}{l}
0 \quad \text { if } \quad x \leq 0 \\
\frac{k}{\gamma}\left(\frac{x}{\gamma}\right)^{k-1} e^{\left(\frac{x}{\gamma}\right)^{k}} x>0
\end{array}\right\}
$$

When $(\mathrm{k}=1)$ Weibull distribution with two parameter will transferred to Exponential distribution.

$\mathrm{f}(\mathrm{x})=1 / \lambda)$

and its density function as

$$
f(x)=\left\{\begin{array}{ll}
0 & \text { if } x \leq 0 \\
& \text { c. } e^{(-x)}
\end{array}>0\right\}
$$

that its expected value and Variance as that its

$$
\mu=E(X)=\frac{1}{\gamma} \quad \sigma(\mathrm{X})=\beta^{2}(\mathrm{x})=\frac{1}{x^{2}}
$$

Then we get a special form for Weibull distribution when $(\theta$ $=0)$ and $(\mathrm{K}=1)$ and $\lambda=(1 / \mathrm{x})$ because Weibull distribution connecting to three parameter beside the Exponential distribution in the scientific application. Weibull distribution deemed as extremist probability distributions that is given as Distributive distribution for the minimum value for a big number of independent random variables, It's from the continues Probability distributions that called test distributions like $\left({ }^{2}\right)$ chi- square distribution, distribution $t$ Student calledt distribution and F distribution. Based on the aforementioned, depending on potential distribution for the extremist values, we can express generalized Weibull distribution by a distributional function for the random variable $\mathrm{x} .[10]$

$$
\begin{aligned}
& G(X ; \theta, \alpha, k)=P(X \leq X)=\exp \left[-\left(1-\frac{k}{\theta}(X-\alpha)^{\frac{1}{k}}\right)\right] \\
& \quad k \neq 0
\end{aligned}
$$

$$
G(X ; \theta, \alpha)=\exp [(\exp (-\gamma((X-\alpha) / \theta) \delta)] k=0 \cdot .(9)
$$

As it represents

$\theta$ scale parameter, $\mathrm{k}$ shape parameter, $\beta$ location parameter.

It is also a relationship between Generalized Weibull distribution and extremist values distribution are $(\mathrm{T}=-\mathrm{x})$, ( $\mathrm{T}$ represents random variable of generalized Weibull distribution, therefore (9)

$\mathrm{P}(\mathrm{T} \leq \mathrm{t})=\mathrm{P}(-\mathrm{X} \leq \mathrm{x})=1-\mathrm{G}(\mathrm{x} ; \theta, \alpha, \mathrm{k})$

$\mathrm{t}$ represents the random value and it's limited from bottom [ , ] so we can get the distributional function for generalized Weibull distribution with three parameter and two parameter, we shall replace $(\mathrm{x})$ with -1 and $(-\alpha)$ value with $(\beta)$ in the relations (7) and (8)It becomes our[1]

$$
\begin{gathered}
F(t ; \theta, \beta)=1-\exp \left[\left(1+\frac{k}{\theta}(1-\beta)^{\frac{1}{k}}\right] k \neq 0\right. \\
F(t ; \theta, \beta)=1-\exp \left[\left(-\exp \left(\frac{t-\beta}{\theta}\right)\right] k=0\right.
\end{gathered}
$$

To get probability density function for generalized Weibull distribution with three and two parameter, we take derivative for both relations (7) and (8), the result

$$
\begin{array}{r}
f(X ; \theta, \beta, k)=\frac{1}{\theta}\left(1+\frac{k}{\theta}(t-\beta)^{\left(\frac{1}{k}-t\right)} \exp [-(1+\right. \\
\left.\left.\frac{k}{\theta}(t-\beta)^{\frac{1}{k}}\right)\right] k \neq 0 \\
f(t ; \theta, \beta)=\frac{1}{\theta} \exp \left[\frac{t-\beta}{\beta}\right] \exp \left(-\exp \left[\frac{t-\beta}{\theta}\right]\right) \quad k . . .(11)
\end{array}
$$

Will be the based on that we can write the Reliability Function as generalized Weibull distribution with three and two parameter

$$
R(t)=1-\exp \left(-\exp \left(\frac{t-\beta}{\theta}\right)\right)
$$

and risk average

$$
H(t)=\frac{1}{\theta} \exp \left[\frac{t-\beta}{\theta}\right]
$$

\subsection{Liner Estimation}

$\mathrm{T}$ would be random variable subject to generalized Weibull distribution with two parameter according to the relation (10)

$$
F(t ; \theta, \beta)=1-\exp \left[\left(-\exp \left(\frac{t-\beta}{\theta}\right)\right] k=0\right.
$$

$\left(t_{1}, t_{2}, \ldots . . t_{n}\right)$ let them be the data which subject to generalized Weibull distribution with two parameter hen we can estimate its indicator as following (8)[2]

$$
\hat{\theta}=\sum_{i=1}^{n} C_{i} t_{i}, \hat{\beta}=\sum_{i=1}^{n} a_{i} t_{i} \quad(i=1,2, \ldots . n)
$$

Since $\mathrm{i}$ is $(1,2, \ldots \ldots \ldots$ b) ci ,aiis liner weighting faction, therefore we write the mathematical relation for the reversed function of generalized Weibull distribution with two parameter as.[7]

knowing that;

$$
t_{p}=\beta+\theta X_{i j}
$$

$$
X_{p}=\ln (-\ln (1-p))
$$

Then we can find the value of both $\theta$ and $\beta$ as they represent the inclination and the volunteer in regression equation (15). Through several methods, we can estimate two indicators generalized Weibull distribution but we will only use Wight method here which based on regression analyses theory, through converting the ofCumulative distribution function the relation (15),To formula Simple Linear Regression Model.

$$
f(t ; \theta, \beta)=1-\exp \left[-\exp \left(\frac{t-\beta}{\theta}\right)\right]
$$

Or to write

$$
1-f(t ; \theta, \beta)=\exp \left[-\exp \left(\frac{t-\beta}{\theta}\right)\right]
$$

by using the above function logarithm twice in order $\ln \{-\ln [1-f(t ; \theta, \beta)]\}=\left(\frac{t-\beta}{\theta}\right)$

to $\left(t_{n} \ldots . . t_{3}>t_{2}>t_{1}\right)$ which is an arrange observations for specific random sample its size is $(\mathrm{n})$. When we right the 


\section{International Journal of Science and Research (IJSR) \\ ISSN (Online): 2319-7064}

Index Copernicus Value (2016): 79.57 | Impact Factor (2015): 6.391

previous relation, after taking the alogarithm twice as follows:[5]

$$
\ln [-\ln [1-f(t ; \beta, \theta)]]=\frac{t i-\beta}{\theta}
$$

Such as

$$
t\left(f_{i}\right)=\beta+\ln \left[-\ln \left(1-\hat{f}_{i}\right)\right]
$$

if we put xi instead of $\ln \left[-\ln \left(1-\hat{f}_{i}\right)\right]$ and $y i$ instead of $t\left(f_{i}\right)$ When liner regression equation became as follows in $y_{i}=\beta+\theta X_{i}$

That is, since $\hat{f}_{i}:$ is a point for $f(t ; \beta, \theta)$ which is fund through one of the following ways.

$$
\begin{gathered}
1-\hat{f}_{i}=\frac{1}{n+\frac{1}{3}} \\
2-\hat{f}_{i}=\frac{i-\frac{3}{8}}{n+0.25} \\
3-\hat{f}_{i}=\frac{i-0.5}{n}
\end{gathered}
$$

To aim Estimate generalized Weibull distribution two parameter according to Wight method by using last squares method the amount shall be,

$$
G(\beta, \theta)=\sum_{i=1}^{n} t f_{(i)}-\beta-\theta\left\{\ln \left[\ln \left[1-\widehat{f}_{i}\right]\right\}\right.
$$

so we get above invariables regression equation by applying the following relation

$$
\begin{aligned}
& \hat{\theta}=\frac{\overline{\sum_{i=1}^{n}}\left(X_{i}-\bar{X}\right)\left(Y_{i}-\bar{Y}\right)}{\sum_{i=1}^{n}\left(x_{i}-\bar{X}\right)} \\
& \beta=\bar{Y}-\hat{\theta} \bar{X} \\
& \text { That is } \\
& \bar{X}=\frac{\sum_{i=1}^{n} X_{i}}{n} \quad, \bar{Y}=\frac{\sum_{i=1}^{n} Y_{i}}{n} \\
& Y_{i}=t\left(f_{i}\right)
\end{aligned}
$$

which represents values average of observations studied phenomenon which organized ascending

$\mathrm{xi}=\ln \left[-\ln \left(1-\widehat{f}_{1}\right)\right]$

$\hat{\beta}=\frac{i-0.5}{n}$

We also can get it through estimating the first rank of Taylor serial of ascending organized data.

$$
\begin{aligned}
& Z_{i}=\ln \left(-\ln \left(-P_{i}\right)\right) \\
& i P=\beta+\theta Z_{i} \\
& \frac{\partial t}{\partial \beta}=1 \quad \frac{\partial i}{\partial \theta}=Z_{i} \\
& f(a+h)=f(a)+h i f(a)+h i \hat{F}(a) \\
& f(a)=\beta_{i j}+\theta_{i j} Z_{i} \\
& F(a)=\beta_{i j}+\theta_{i j} Z_{i} \\
& E\left(t_{i}\right)=\beta_{i j}+\theta_{i j} Z_{i j}+\left(\beta-\beta_{i j}\right)+\left(\theta+\theta_{i j}\right) Z_{i j} \\
& E\left(t_{i}\right)=\beta_{i j}+\theta_{i j} Z_{i j}+\left(\beta-\beta_{i j}\right)+\left(\theta Z_{i j}+\theta_{i j} Z_{i j}\right) \\
& E\left(t_{i}\right)=\beta+\theta Z_{i j}
\end{aligned}
$$

We can get it by using OLS method (which based on matrixes). Estimating parameter generalized Weibull distribution, where the values will be extracted $(\theta, \beta)$ from the following equation[6]

$$
\left[\begin{array}{l}
\beta \\
\theta
\end{array}\right]=\left[\begin{array}{ll}
\hat{H} & H
\end{array}\right]^{-1} \hat{H} t_{i} Z
$$

That is
$H=\left[\begin{array}{cc}1 & Z_{1} \\ 1 & Z_{2} \\ 1 & Z_{n}\end{array}\right]$

In order to know the data relevance of any studied phenomenon of generalized Weibull distribution, it is possible to subject these data to suitable relevance test based on values schedule for Weibull distribution with two parameter and extreme value distribution. It is possible to reach to $\mathrm{A}^{\wedge} 2 \mathrm{n}$ schedule of distribution by the following[2],[9]

$\mathrm{F}(t ; \theta, \beta)=1-\exp \left[-\exp \left(\frac{t-\hat{\beta}}{\theta^{*}}\right)\right] \quad K \neq 0$

Assuming that

$$
Z_{i}=-\exp \left(\frac{t i-\beta^{n}}{\theta^{\wedge}}\right)
$$

this imposes in the equation (19) to have the relation $f(t ; \theta, \hat{\beta})=1-\exp (\mathrm{zi})$

therefore, we will reach to schedule of distribution with two parameter by applying

$A_{n}^{2}=n-2\left[\sum_{i=1}^{n} \ln \left(f_{i}\right)+\left(1-P_{i}\right) \ln \left(1-f_{i}\right)\right)$.

That is

$P_{i}=\frac{t-0.5}{n} \quad t=1,2,3, \ldots \ldots, n$

\section{The Practical Application}

\subsection{Introduction}

This study focuses on maximum temperature degrees and rains amounts in Baghdad during ten years (2000-2010), In the winter months lbased on Meteorological Network of Iraqi Ministry of Agriculture. By taking Weibull distribution and estimate its parameter by using minimum squares method in finding the probability Expected for maximum temperature degrees and rains amounts schedule and we used the data of monthly averages for each maximum temperature degree and rains amounts in Baghdad in Winter (December, January, February) during the study period from Meteorological Network of Iraqi Ministry of Agriculture, we reached the below listed data in table (1) as follows:

Table 1: which ascending organized for the average temperature and rain amounts for winter at Baghdad during the studying period (2000-2010).

\begin{tabular}{|c|c|}
\hline Rains Amounts & Maximum Temperature Degrees \\
\hline 12.5 & 8.60 \\
\hline 18.9 & 9.34 \\
\hline 20.1 & 9.52 \\
\hline 21.0 & 10.53 \\
\hline 21.7 & 12.65 \\
\hline 29.5 & 12.75 \\
\hline 35.5 & 13.85 \\
\hline 34.7 & 14.87 \\
\hline 50.7 & 14.53 \\
\hline 80.9 & 15.13 \\
\hline
\end{tabular}

According to the aforementioned in the theoretical side of generalized Weibull distribution and estimating its parameter based on minimum squares method, depending on

\section{Volume 6 Issue 12, December 2017}

\section{www.ijsr.net}

Licensed Under Creative Commons Attribution CC BY 


\section{International Journal of Science and Research (IJSR) \\ ISSN (Online): 2319-7064}

Index Copernicus Value (2016): 79.57 | Impact Factor (2015): 6.391

the statistical program (STATGRAPHICS). After Ascending ordering of the data regarding maximum temperature degree and rains amounts in Baghdad in winter $(2000-2010)$ as shown in the table No. 1. We distributed generalized Weibull with two parameters $\beta, \theta$ for these data by applying the relation (17), relation (16) that we get as following:

Table 2: show the estimated values for generalized Weibull distribution two parameters

\begin{tabular}{|l|l|l|}
\hline parameter & rains amounts & maximum temperature degree \\
\hline$\beta$ & 40.053 & 12.23 \\
\hline$\theta$ & 10.90 & 5.01 \\
\hline
\end{tabular}

and through using n Anderson Darling test according to relation (19), if accounted to confirm the relevance of maximum temperature degree and rains amounts according to the estimated values in table No.2 of Weibull distribution with two parameter. Where value for the temperature (0.52) while its value for rains (1.005). by comparing these values with the table value at level $\alpha=(0.05)$ which equals to (0.677), we accept the accounted maximum temperature degree data less than its table value. This means that data disrupted generalized Weibull distribution with two parameter. While we don't accept rains amounts data because accounted value larger than table value, it won't distributed as generalized Weibull distribution with two parameter through applying the relation (15) on each maximum temperature average and rains amount average which is estimated to know the accuracy of minimum squares method in estimating two generalized Weibull distribution indicators. We reach to the stated in table No. 3 .

Table 3: show the estimated values for maximum temperature and rains amount estimated values of rains estimated values of temperature degrees

\begin{tabular}{|c|c|}
\hline $\begin{array}{c}\text { estimated values of } \\
\text { rains }\end{array}$ & $\begin{array}{c}\text { estimated values of } \\
\text { temperature degrees }\end{array}$ \\
\hline 6.32 & 9.4 \\
\hline 11.45 & 10.4 \\
\hline 15.4 & 10.5 \\
\hline 19.1 & 11.6 \\
\hline
\end{tabular}

\begin{tabular}{|c|c|}
\hline 22.0 & 12.5 \\
\hline 24.5 & 13.6 \\
\hline 31.36 & 14.9 \\
\hline 40.5 & 14.6 \\
\hline 43.5 & 14.9 \\
\hline 55.3 & 14.8 \\
\hline
\end{tabular}

From table (1) and (3) the real values approach from estimated values of temperature degrees because the data of generalized Weibull will be distributed and real values will not approach the estimated values of rains amounts because the rains do not distributed as Weibull distribution. We also find the expected probability to achieve maximum temperature average during $\mathrm{N}$ year depending on applying the relation 15 and the estimated values $\beta, \theta$ for maximum temperature average given in table No. 2

$$
\mathrm{G}=1-[-f(t)]^{n}
$$

for example if the maximum temperature for winter in Baghdad was (8.01) then

$\mathrm{F}(\mathrm{t})=0.0055$

The probability of maximum temperature within two years is $(0.01)$ and within 4 years is $(0.3)$ and so the rest statistics. Upon to that, we found the expected for maximu probability temperatures according to the data shown in table no. 1 for $\mathrm{N}$ years that takes the statistics $(2,4,6,8,10,12,14,16,18,20)$ as shown in the following table No. 4

\section{Conclusion}

We can use the linear regression in estimating parameter Wie bill generalized distribution marks for what it gives of reasonable results.

We can use Wie bill generalized distribution in forecasting, we recommend to use it in suitable natural phenomena for this distribution.

The ability to make continues surveys for the climate in Iraq in light of the common climate changes for surveying wetness, dust, global warming and etc.

Table 4: Shows the expected possibility of the maximum temperature for $\mathrm{N}$ years

\begin{tabular}{|c|c|c|c|c|c|c|c|c|c|c|c|}
\hline No. & Tamp. & Year 2 & Year 4 & Year 6 & Year 8 & Year 10 & Year 12 & Year 14 & Year 16 & Year 18 & Year 20 \\
\hline 1 & 9.03 & 0.01 & 0.3 & 0.05 & 0.06 & 0.07 & 0.09 & 0.11 & 0.12 & 0.13 & 0.14 \\
\hline 2 & 10.13 & 0.3 & 0.54 & 0.65 & 0.66 & 0.67 & 0.69 & 0.75 & 0.78 & 0.82 & 0.81 \\
\hline 3 & 10.02 & 0.4 & 0.53 & 0.64 & 0.67 & 0.68 & 0.69 & 0.72 & 0.79 & 0.84 & 0.85 \\
\hline 4 & 12.3 & 0.46 & 0.61 & 0.75 & 0.77 & 0.78 & 0.79 & 0.81 & 0.83 & 0.84 & 0.85 \\
\hline 5 & 12.4 & 0.47 & 0.60 & 0.74 & 0.78 & 0.79 & 0.81 & 0.82 & 0.84 & 0.85 & 0.86 \\
\hline 6 & 12.6 & 0.47 & 0.74 & 0.73 & 0.79 & 0.81 & 0.82 & 0.84 & 0.85 & 0.91 & 0.95 \\
\hline 7 & 13.30 & 0.50 & 0.75 & 0.71 & 0.81 & 0.83 & 0.84 & 0.85 & 0.86 & 0.94 & 0.96 \\
\hline 8 & 13.40 & 0.52 & 0.86 & 0.87 & 0.88 & 0.89 & 0.91 & 0.92 & 0.94 & 0.94 & 0.96 \\
\hline 9 & 14.50 & 0.61 & 0.84 & 0.85 & 0.89 & 0.89 & 0.92 & 0.94 & 0.95 & 0.96 & 0.97 \\
\hline 10 & 15.6 & 0.69 & 0.81 & 0.83 & 0.89 & 0.89 & 0.89 & 0.89 & 0.89 & 0.89 & 0.89 \\
\hline
\end{tabular}

\section{References}

[1] N. R. Mann, "Exact three-order-statistic confidence bounds on reliablelife for aWeibull model with progressive censoring," J. Amer. StatisticalAssoc., vol. 64, pp. 306-315, 1969.

[2] D. R. Thomas and W. M. Wilson, "Linear order statistic estimation forth two-parameterWeibull and extreme value distributions from Type-IIprogressively censored samples," Technometrics, vol. 14, pp. 679691,1972 .

[3] G. C. Montanari and M. M. Cacciari, "Progressivelycensored agingtests on xlpe-insulated cable models," IEEE Trans. ElectricalInsulation,vol. 23, pp. 365-372, 1988.

\section{Volume 6 Issue 12, December 2017}




\section{International Journal of Science and Research (IJSR) \\ ISSN (Online): 2319-7064}

Index Copernicus Value (2016): 79.57 | Impact Factor (2015): 6.391

[4] A. garcia, J.L. torres, E. prieto and A. defranciscofittingwinddistribution : A casestudy Solar Energy Vol. 62, No. 2, pp. 139-144, 1998

[5] Rehman S., Halawani T. O. and Husain T. (1994) Weibull parameters for wind speed distribution in Saudi Arabia Solar Energy 3, 6, 473-479.

[6] Stevens M. J. M. and Smulders P. T. (1979) The estimation of the parameters of the Weibull wind speed distribution for wind energy utilization purposes. Wind Engng 3, 2, 132-145

[7] H. K. T. Ng Parameter Estimation for a Modified WeibullDistribution, for Progressively TypeIICensored Samplesieee transactiononreliability, vol. 54, no. 3, September 2005

[8] Nelson,Jr.Ralph, 2008, " Dispersing Prowders in Liquids, Part 1,Chap6: Particle Volume Distribution". http:/www.erpt.org/014Q/nelsa-06.htm.Retrieved.

[9] Kahadawala, C.,(2006), Generalization of the weibull Distribution: the add weibullfamily, Statistical modeling ,6;pp:265-277

[10] Gunbel, E.J., 1958,Statistics of extremes, New York

Volume 6 Issue 12, December 2017

www.ijsr.net 